\title{
Tools to Measure the Technological Capabilities of the Aerospace Industry
}

\author{
Acela Castillón-Barraza ${ }^{1}$ (D), Alvaro González-Angeles ${ }^{2}$ (iD), Fernando Lara-Chavez² (iD), Ismael Mendoza-Muñoz ${ }^{2}$ (iD \\ ${ }^{1}$ Instituto Tecnológico de Mexicali (Mexico) \\ ${ }^{2}$ Facultad de Ingeniería, Universidad Autónoma de Baja California (UABC) (Mexico) \\ acelacastillon@hotmail.com,gangelesa@gmail.com,lara.fernando@uabc.edu.mx,ismael.mendoza@uabc.edu.mx
}

Received: June 2018

Accepted: October 2018

\begin{abstract}
:
Purpose: The following article describes steps along with a mathematical model to determine the technological capability of the aerospace industry of Mexicali in the area of design (ICTD) and manufacturing (ICTM)

Design/methodology/approach: This model was performed by weighted variables using factor analysis to identify technological capacities of Small and medium-sized enterprises (SMEs) and compare them with those that must be accomplish to become suppliers for transnational industry (TNCs).

Findings: The results suggest that SMEs must realize a comparative table QFD of their current capabilities and the requirements established by transnational corporations, to create a strategic plan that includes; certifications (AS 9000, NAP CAP, Belts, ISO, Six Sigma), software acquisition and updated equipment necessary for reducing the technological gap. Additionally, it is recommended the integration of clusters of enterprises SMEs for the strengthening of technological capacities.
\end{abstract}

Originality/value: Up to we know, there is not similar model for measuring technological capabilities of aerospace industry.

Keywords: SMEs, technological capabilities index, technology transfer, diagnostics, supplier development

\section{To cite this article:}

Castillón-Barraza, A., González-Angeles, A., Lara-Chavez, F., \& Mendoza-Muñoz, I. (2018). Tools to measure the technological capabilities of the aerospace industry. Journal of Industrial Engineering and Management, 11(4), 769-775. https://doi.org/10.3926/jiem.2669

\section{Introduction}

Latin America based its industrialization mainly in the acquisition of productive capacity by negotiating technology with foreign companies, (Unasur, 2014). There is evidence that some companies experienced technological learning processes with which they acquire technological capabilities (Dagnino, 2012; Hansen \& Ockwell, 2014; Khayyat \& Lee, 2015). However, this was not enough for technological independence since opening up to globalized world had a significant decrease in the growth of manufacturing activities and consequently resulted in a marked decrease in creation of national manufacturing companies in various sectors. 
In Mexico, specifically the industrialization project in the north border was implemented in the 60's and 70's primarily with the establishment of American factories to aid in the unemployment status in the region. Moreover, to create an industry that could provide services to these companies. The proposal did not work in its initial approach and final scope, remaining limited to the provision of services and infrastructure support for these industries. However, a real achievement was the acquisition and adaptation of techniques and forms of organization for production, and therefore managed to create an organizational culture based on the competences of the normative and productivity with great success, because these companies have achieved great levels of productivity and high quality in the industry.

For the creation of technological capabilities, a base is the understanding of the value chain and the knowledge of the companies of the sector of interest Díaz, Aguilar and de Saá-Pérez (2006). Some researches Chan and Pretorius, (2007) and Cerulli (2014) recognize that innovation and the development of intellectual property are economic engines key. Besides that can no longer rely on the natural resources to be globally competitive; therefore it must stimulate innovation as a key source of competitiveness, through the construction of the intellectual property generated locally linked to its base investigation.

There are some researchers that Saavedra-García (2012) propose a methodology to determine the level of competitiveness of Small and medium-sized enterprises SMEs, considering internal and external factors. The considered factors were the strategic planning, production and operations, quality, marketing, accounting and finance, human resources, environmental management and information systems as well as external orientation indicators in systematic competitiveness. Others offer a model based on the technological capabilities of innovation (ICT), assessing capabilities of R\&D (research and development), technological learning, capacity of resources management, marketing capacity, manufacturing capabilities and strategic Decision capability Aguirre-Ramírez (2010) (Molina-Domene \& Pietrobelli, 2012).

On the other hand, an objective of the regional governments (Baja California, México) is encourage and support SMEs for their integration to the supply chains with manufacturing sector. This could be achieved developing technological capabilities that put them to level of competence of the international sector. The study of the technological capabilities of the manufacturing industry aerospace is feasible and necessary to its development. It has could observe that this industry is very general in its processes but particular in its requirements as the precision and traceability.

Thus, for the formulation of a technological strategy based on technologic approach, it should be determined the degree of correspondence between the technological competences available and that must be obtained. The potentials SMEs that could be suppliers of goods and services should diminish the separation between the high technological skills that possess the large aerospace companies located in our region.

Here, the procedure along with of a mathematical model that can represent and measure the technological capabilities in two factors; design and manufacturing. Using a qualitative methodology of weighting of needs, using factorial analysis to determine the variables of these factors and then calculate an index of technological capability that will represent the extent of the technological gap between Small and medium-sized enterprises (SMEs) and transnational corporations (TNCs).

\section{Experimental Analysis}

The methodology followed, for the determination of technological capabilities, was through a study of multiple cases where was applied a questionnaire divided in two important and representative areas, manufacturing and design.

The questionnaires were elaborated with multiple-choice answers (they can be consulted and answered on line) (Castillón-Barraza, 2016). It was developed a model to estimate the rate of technological capacity through variables that measure 4 elements: effectiveness of use, evaluation or quality, maintenance or improvement and production planning within manufacturing (VM), and design variables (VD) (described in Table 1). 


\begin{tabular}{|c|l|l|}
\hline No. & \multicolumn{1}{|c|}{ Element } & \multicolumn{1}{c|}{ Description of element } \\
\hline 1 & Use effectiveness & $\begin{array}{l}\text { Ability to carry out, to use and to control conversion technologies of the main and } \\
\text { auxiliary processes. }\end{array}$ \\
\hline 2 & Evaluation or quality & $\begin{array}{l}\text { Ability to carry out quality warranty, inspection and stock control, inventories and work } \\
\text { in progress. }\end{array}$ \\
\hline 3 & $\begin{array}{l}\text { Improvement or } \\
\text { maintenance }\end{array}$ & $\begin{array}{l}\text { Ability to solve problems, for improvement applied to preventive maintenance, } \\
\text { establishment of abrupt maintenance and of routine }\end{array}$ \\
\hline 4 & Production planning & Ability to perform production planning, and maintenance programming for equipment \\
\hline
\end{tabular}

Table 1. Description of the elements by dimension for DV and MV.

Each indicator within technological ability has elements that can be measured:

- Hardware (HW): Is the built-in machines, tools and auxiliary systems technology.

- Software (SF): Technology not physically incorporated and presented in computer programs, manuals, standards and others.

- Orgware (OG): Organizational structure, processes, procedures, policies and operational strategies.

- Humanware (HW): This refers to staff that have know-how. Skills and tactical knowledge (Velosa-García, 2011).

The questionnaires measure the variable using the indicators mentioned above, to be able to approximate the technological capabilities to a mathematical model using the factorial analysis in two stages: an initial Exploratory Factory Analysis (EFA) and another Confirmatory Factor Analysis (CFA).

Exploratory factor analysis (EFA) could be described as orderly simplification of interrelated measures. EFA, traditionally, has been used to explore the possible underlying factor structure of a set of observed variables without imposing a preconceived structure on the outcome. By performing EFA, the underlying factor structure is identified. Confirmatory factor analysis (CFA) is a statistical technique used to verify the factor structure of a set of observed variables. CFA allows the researcher to test the hypothesis that a relationship between observed variables and their underlying latent constructs exists(Suhr, 2006).

Obtaining an equation for the design dimension:

$$
D V_{i}=a_{n m} P 1+a_{n m} P 2+a_{n m} P 3 \ldots a_{n m} P_{m} \therefore D V_{i}=\sum_{i=P i}^{P m} a_{m} * P_{m}
$$

Where:

$$
\begin{aligned}
& \mathrm{n}=1,2,3 \mathrm{o} \text {; } \text { Technological Capacity Component } \\
& \mathrm{a}_{\mathrm{nm}}=\text { factor loading by design dimension question } \\
& \mathrm{P}_{\mathrm{m}}=\text { Value obtained from the survey } \\
& \mathrm{m}=\text { Number of questions }
\end{aligned}
$$

And for manufacturing dimension:

$$
\begin{aligned}
& \mathrm{MV}_{\mathrm{i}}=\mathrm{b}_{n m} \mathrm{P} 1+\mathrm{b}_{\mathrm{nm}} \mathrm{P} 2+ \\
& \mathrm{b}_{n m} \mathrm{P} 3 \ldots \mathrm{b}_{\mathrm{nm}} \mathrm{P}_{\mathrm{m}}
\end{aligned}
$$$$
\therefore \mathbf{V M}_{\mathbf{i}}=\sum_{\mathbf{i}=\mathbf{P i}}^{\mathbf{P m}} \mathbf{b}_{\mathbf{m}} * \mathbf{P}_{\mathbf{m}}
$$

Where:

$\mathrm{n}=1,2,3$ or 4; Component of technological capacity

$\mathrm{b}_{\mathrm{nm}}=$ factor loading by manufacturing dimension question

$\mathrm{P}_{\mathrm{m}}=$ Value obtained from the survey

$\mathrm{m}=$ Number of questions 
Later to the evaluation of the DV and MV, the indexes of technological capabilities will be calculated according to the Equations 3 and 4.

For the dimension of design is obtained Index of Capacity Technology design:

$$
I C T_{D}=D V 1+D V 2+D V 3+D V 4
$$

For the dimension of manufacturing is obtained Index of Capacity Technology Manufacturing:

$$
\mathrm{ICT}_{\mathrm{M}}=\mathrm{MV} 1+\mathrm{MV} 2+\mathrm{MV} 3+\mathrm{MV} 4
$$

\section{Results and Discussions}

The survey was realized to four transnational industries called En and two SMEs. The obtained results were processed by means of the Statistical Package for the Social Sciences (SPSS software), obtaining the factor loadings for every question $\mathrm{a}_{\mathrm{nm}}$. Later, the variables of design and manufacture of every aerospace company were obtained by means of the Equations 1 and 2. After, these results were substituted in the Equations 3 and 4, obtaining the indicators of technological capacity of design and manufacture for every studied company, (Table 2).

Due to necessity to compare in the same order of magnitude the two dimensions, the data of the technological capability indicator for design and manufacturing were normalized on a scale of 0 to 1 . This means that, if a company is in the lowest level it will have the value of 0 and if it obtains the maximum score its value will be 1 . Later the ICT $\mathrm{T}_{\mathrm{D}}$ and $\mathrm{ICT}_{\mathrm{M}}$ will be compared to evaluate the level of technological capability of every group and generate graphs and conclusions on the aerospace sector.

In Table 2, it can see the comparison between the indexes of technological capacity design dimensions (ICT $\mathrm{D}_{\mathrm{D}}$ ) and manufacturing $\left(\mathrm{ICT}_{\mathrm{M}}\right)$ for transnational corporations(TNCs) and small and medium sized enterprises (SMEs).

Figure 1 shows the degree of technological capability of all studied firms. It can see clearly the gap between each company. It can observe that local multinational aerospace companies are located in the highest levels (3 and 4) in design and manufacture of its products. This means a high value, with reference to the established scale. It is also observed that the two of the four analyzed transnational (E1 and E2) have a balanced development of technological capabilities in design and manufacturing, levels three and four respectively. The other 2 (E4 and E3) possess more design orientation and are located between levels 3 and 4 .

\begin{tabular}{|l|r|r|}
\hline \multicolumn{2}{|c|}{ Indexes of Technological Capabilities } \\
\hline Companies & $\begin{array}{c}\text { X } \\
\text { ICT }_{\text {D }}\end{array}$ & \multicolumn{1}{|c|}{\begin{tabular}{c} 
ICT $_{\text {M }}$ \\
\hline Vmin
\end{tabular}} \\
\hline Vmax & 0.00 & 0.00 \\
\hline E1 & 1.00 & 1.00 \\
\hline E2 & 0.90 & 0.94 \\
\hline E3 & 0.60 & 0.56 \\
\hline E4 & 0.90 & 0.69 \\
\hline SME1 & 0.78 & 0.43 \\
\hline SME2 & 3.79 & 3.42 \\
\hline
\end{tabular}

Table 2. Technological Capabilities Indexes of surveyed aerospace 


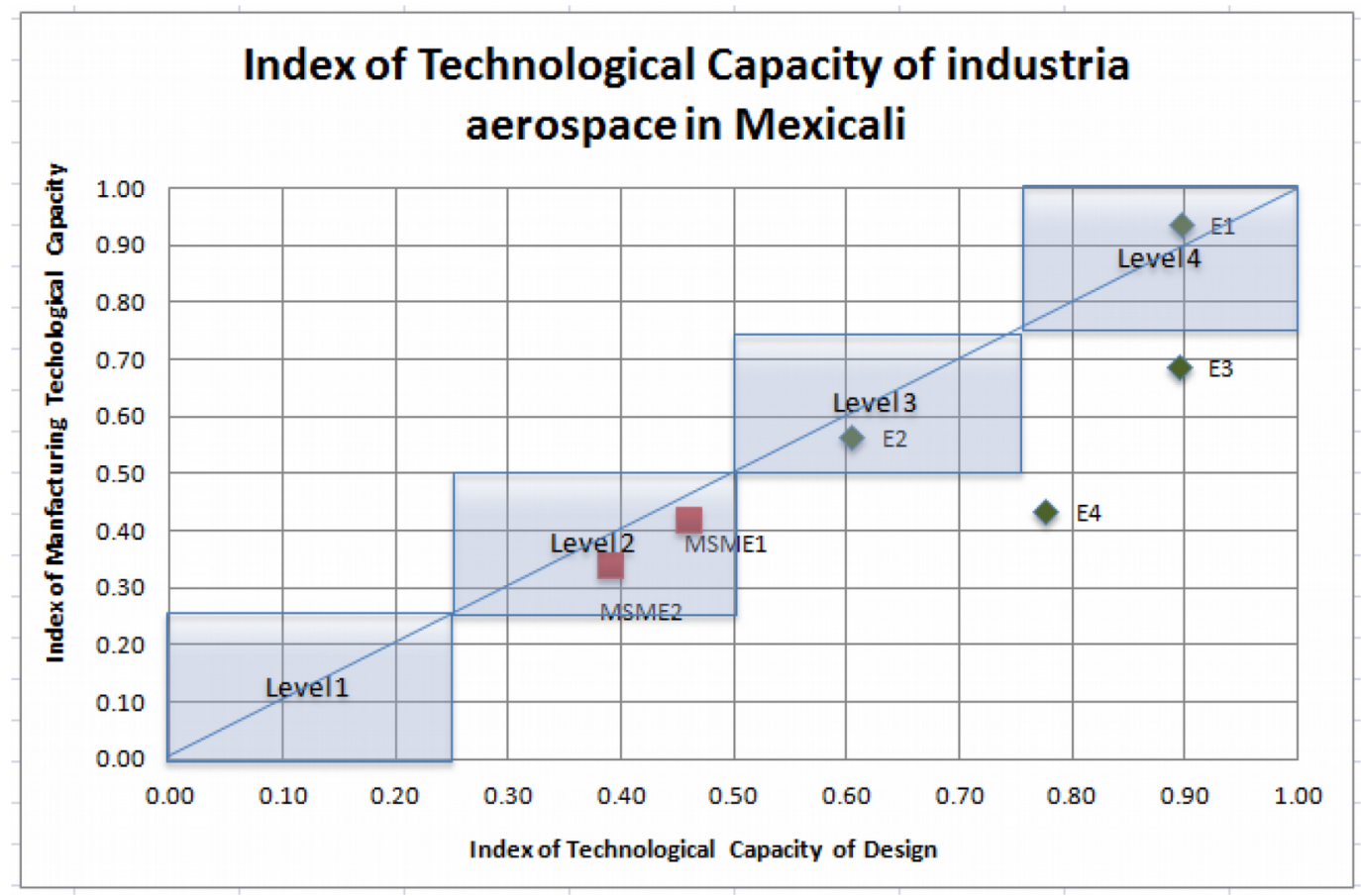

Figure 1. Matrix Technology Capability Indices aerospace Mexicali

On the other hand, the two studied SMEs are positioned in level 2 with a slightly design orientation. It can clearly observe the technological breakthroughs and innovation gap between TNCs and local SMEs companies.

The manufacturing and design index obtained from companies primarily reflect the maturity of core competence that was built by an organizational culture throughout its operational life in the region.

The main components of this core competence to consolidate an own organizational culture are as follows: 1) Capacity of assimilation and adaptation of the production model of the corporation. 2) Bidirectional adaptation between both cultures. 3) Training of specialized human resources and obtaining certifications in the quality area (AS 9000, NAP CAP, Belts, ISO, Six Sigma, proprietary techniques quality companies etc.). 4) Education and training in manufacturing technologies and production with which it has achieved to be leaders in the market of the aerospace industry (materials: steel and aerospace aluminums, titanium, composites and own patented materials, Manufacturing CNC, assembly, metrology, welding, geometric tolerances, etc.). Adaptation of the above mentioned, it is when you can see the competitive advantage that make a company be located in specific region and not in another country.

Consequently, if a small company desires to have supplies services with a large one, this must realize an analysis of capacities and create a comparative table as QFD (Quality function deployment). This table must contain the current capabilities of SME and the requirements established by transnational, in order to receive services or products. Depending on matches and missing must create a strategic plan that includes; accreditations, certifications, software acquisition and updated equipment necessary for the leveling of the corresponding index of local small business.

From realized analysis, it can conclude that the development and the level of technological capacity must be aligned by the characteristics of the company, the sector orientation and manufacture strategy. It is important to highlight there are different types of technological gaps that must be diminished by strategies that attend o the origin of the gaps.

This method can be used to determine the technological capacities for companies of other sectors, adapting the questionnaire to the needs of the sector to be analyzed. 
Thus, each new company that wants to be assessed shall be only answer the questionnaire by substituting your answers into the equation getting an assessment about design and manufacturing indicators to determine and compare them with already previously evaluated companies.

\section{Conclusion and Recommendations}

The present study developed a measurement tool for capacity technology index of the aerospace industry. For analyzed transnational industries two (E2 and E1) have a development of technological capacities more balanced so much on design as on manufacture level 3 and level 4 respectively. The others two have a level between 3 and 4 but faced more to the design.

The companies SMEs have lower technological capacities (almost to half of the transnational ones) slightly orientated to design. SMEs must realize a comparative table QFD of their current capabilities and the requirements established by transnational, to create a strategic plan and to reduce the technological gap, depending on matches and missing. Look for relationship with the universities, support in governmental programs such as CONACyT -PEI, FOMIX, INADEM, and other International funding programs.

Additionally, it is recommended the integration of clusters of enterprises SMEs for the strengthening of technological capacities.

\section{Declaration of Conflicting Interests}

The authors declared no potential conflicts of interest with respect to the research, authorship, and/or publication of this article.

\section{Funding}

The authors would like to thanks CONACyT-México for given support to carry out this work under grant No. CVU 172568.

\section{References}

Aguirre-Ramírez, J.J. (2010). Metodología para medir y evaluar las capacidades tecnológicas de innovación aplicando sistemas de lógica difusa caso fábricas de software, 91.

Castillón-Barraza, A. (2016). Technological Capacities Surveys.

Cerulli, G. (2014). The impact of technological capabilities on invention: An investigation based on country responsiveness scores. World Development, 59, 147-165. https://doi.org/10.1016/j.worlddev.2014.01.019

Chan, K.Y., \& Pretorius, M.W. (2007). Developing technological capability in science parks: A networking model approach. Portland International Conference on Management of Engineering and Technology, 565-573. https://doi.org/10.1109/PICMET.2007.4349371

Dagnino, R. (2012). Why science and technology capacity building for social development? Science and Public Policy, 39(5), 548-556. https://doi.org/10.1093/scipol/scs068

Díaz, L., Aguilar, I., \& de Saá-Pérez, P. (2006). El conocimiento organizativo tecnológico y la capacidad de innovación. Evidencia para la empresa industrial española. Cuadernos de Economía y Dirección de La Empresa, 33-59.

Hansen, U.E., \& Ockwell, D. (2014). Learning and technological capability building in emerging economies: The case of the biomass power equipment industry in Malaysia. Tecbnovation, 34(10), 617-630. https://doi.org/10.1016/j.technovation.2014.07.003

Khayyat, N.T., \& Lee, J.D. (2015). A measure of technological capabilities for developing countries. Technological Forecasting and Social Change, 92, 210-223. https://doi.org/10.1016/j.techfore.2014.09.003

Molina-Domene, M.A., \& Pietrobelli, C. (2012). Drivers of technological capabilities in developing countries: Aneconometric analysis of Argentina, Brazil and Chile. Structural Change and Economic Dynamics, 23(4), 504-515. https://doi.org/10.1016/j.strueco.2011.11.003 
Saavedra-García, M.L. (2012). Una propuesta para la determinación de la competitividad en la pyme latinoamericana. Pensamiento \& Gestión, 6276, 93-124.

Suhr, D. (2006). Exploratory or confirmatory factor analysis? Statistics and Data Analysis, 1-17.

https://doi.org/10.1002/da.20406

Unasur. (2014). Ciencia, tecnología, innovación e industrialización en América del Sur: hacia una estrategia regional. (70-84). Rio de Janeiro.

Velosa-García, J.D.E. (2011). Sector Metalmecánico Colombiano. Universidad Nacional de Colombia.

Journal of Industrial Engineering and Management, 2018 (www.jiem.org)

\section{(c) (1) (8)}

Article's contents are provided on an Attribution-Non Commercial 4.0 Creative commons International License. Readers are allowed to copy, distribute and communicate article's contents, provided the author's and Journal of Industrial Engineering and Management's names are included. It must not be used for commercial purposes. To see the complete license contents, please visit https://creativecommons.org/licenses/by-nc/4.0/. 